\title{
Vivências de uma coordenadora de mentoria em 20 anos de experiência
}

\author{
Experiences of a mentoring coordinator in 20 years of practice
}

Emirene Maria Trevisan Navarro da Cruz' (10) | emirene.cruz@edu.famerp.br

\section{RESUMO}

Introdução: A autora, após 52 anos de atividade docente em Psicologia Médica e Psiquiatria, descreve suas vivências desde o início do Programa de Tutoria/Mentoria por ela implantado em 2000.

Desenvolvimento: Cita o "Curso de iniciação para tutores/mentores" e o desenrolar do processo de mentoria, os objetivos, as dificuldades enfrentadas e as razões pelas quais os mentores ainda se debruçam sobre os alunos, na incrível jornada da formação médica.

Conclusão: Ficou bem evidente, por relatos de tutores e alunos, que essa é uma forma importante de tornar o relacionamento professor-aluno mais amistoso, produtivo e saneador.

Palavras-chave: Aluno de Medicina; Educação Médica; Mentoria; Saúde Mental.

\section{ABSTRACT}

Introduction: After 52 years teaching Medical Psychology and Psychiatry, the author describes her experience of coordinating the Tutoring/Mentoring Program, which she implemented in 2000.

Development: The author addresses the Initiation Course for Tutors/Mentors and the development of the Mentoring process, its objectives, the difficulties faced, and the reasons why mentors still remain so dedicated to the students, on the incredible journey of medical training.

Conclusion: From the feedback given by tutors and students, it became clear that this is an important means of making the professor-student relationship more friendly, productive and healing.

Keywords: Medical Student; Medical Education; Mentoring; Mental Health.

${ }^{1}$ Faculdade de Medicina de São José do Rio Preto, São José do Rio Preto, São Paulo, Brasil.

Editora: Patrícia Lacerda Bellodi.

Recebido em 25/02/21; Aceito em 11/05/21.

Avaliado pelo processo de double blind review. 


\section{INTRODUÇÃO}

Este é um relato de experiências vividas; é uma comunicação em "associação livre" - um ensaio fluente, do coração e da mente, com censura inexistente, para formar uma corrente, que vai ligando outra gente que se importa com... gente.

É a fala de uma professora que, após 52 anos de docência, vai deixar, no final do ano, a Faculdade de Medicina de São José do Rio Preto (Famerp), instituição que viu nascer, crescer e engrandecer, e pela qual se apaixonou... dedicando-se à formação dos alunos e cuidando para que não se infestem, não se infectem, nem se infelicitem...

Sinto-me feliz por ter introduzido na Famerp, em 2000, o Programa de Tutoria/Mentoring ou Mentoria. Esse programa começou com um "Curso de iniciação para tutores/mentores" de 40 horas de duração e apresentação de vários temas pertinentes, discutidos com os 25 docentes inscritos.

Um dos últimos temas foi "Como proceder ao se deparar com relato sobre a possibilidade de tentativa de suicídio ou suicídio de algum aluno, ou ter contato com comportamentos, sintomas ou sinais que apontem para isso". Imediatamente, um professor, exaltado, me interpelou: "Por que discutir isso? Não é assunto para tutores!".

Hoje, ele provavelmente não me faria tal pergunta, pois esse tema tem sido amplamente debatido na literatura médica, e, infelizmente, casos têm acontecido em várias faculdades de Medicina, inclusive na nossa.

Entende-se, entretanto, a dificuldade do contestador, pois não é fácil para um profissional, sendo especialista ou superespecialista em área médica restrita, sem ter antes sido exposto a essa situação particular e sem ter recebido treinamento para lidar com ela, admitir ficar em contato com essa possibilidade, que traz angústia e impotência.

Não se pode exigir que o mentor lide com essas situações (ou outras também difíceis) sem que lhe sejam oferecidas supervisão e sustentação disponíveis e seguras. Alguns mentores julgam prescindir do auxílio, mas o tempo e a tentativa podem mostrar que a ajuda alivia a carga.

\section{DESENVOLVIMENTO}

Nós, docentes, temos nos debruçado sobre o problema do sofrimento do aluno de Medicina, tendo sido esse o bem escolhido tema do $57^{\circ}$ Congresso Brasileiro de Educação Médica (Cobem), cuja temática central foi "Educação Médica Transformadora: Compromisso e Responsabilidade Social". Minha fala foi "Como reconhecer o aluno que sofre?", e colegas deram interessantes contribuições à discussão, salientando que a mentoria tem papel importante na discussão desse tema não só com seus pares, mas também com a direção da escola; eu acrescentaria discutir também com dirigentes dos centros acadêmicos e representantes de classe.

Reunião de tutores pode ser um momento propício para se buscarem soluções novas para problemas antigos e doridos: devemos navegar juntos, solidários nas intempéries, felizes nas conquistas.

Lembro-me de que eu, entre 1988 e 1989, apoiada pelo departamento, tentava criar o Serviço de Orientação Psicológica e Pedagógica ao Aluno (Soppa), e ouvimos de alguém: "O curso já é gratuito e ainda temos que dar assistência psicológica para eles?". Resposta: Temos, sim. E conseguimos! Em 1989! E o Soppa funciona bem, graças ao grande empenho dos psicólogos; temos ainda psiquiatras atendendo, uma tarde por semana, os alunos do ambulatório especial; porém, ainda há escassez de profissionais e muita demanda, com lista de espera. A luta continua!

A mentoria surgiu e se mantém como via possível de modelagem, de interação amistosa professor-aluno e entre discentes, como possível alternativa para sair do anonimato, da solidão. Sentir-se reconhecido na multidão, encontrando apoio, estímulo, encaminhamento, sanando dúvidas e buscando vias de desenvolvimento profissional e pessoal. Bellodi et al. ${ }^{1}$, em seu livro, principal referência para o mentoring em nosso país, assinalam que os alunos buscam a formação para o mundo do trabalho; entretanto, esperam, e isso deve ser seriamente considerado, que a vida universitária lhes traga crescimento pessoal. Isso é muito verdadeiro e se torna claro nos contatos formais e informais com o alunado durante o decorrer do curso. A nosso ver, a mentoria se mostra mais um instrumento capaz de atender a essa necessidade entre nossos estudantes.

Durante todos esses anos, várias pesquisas com tutores e alunos trouxeram sempre de $70 \%$ a $90 \%$ de aprovação do programa. Algumas respostas dos doutorandos, colhidas a cada ano, nos preocupam: "Tutoria é perda de tempo, prefiro estudar" e "Discussões inúteis sobre temas repetidos". Porém, outros relatos nos estimulam a insistir: "Meu tutor substituiu meu pai", "Tutoria foi para mim a melhor experiência da minha vida universitária" e "Me deu outra visão da instituição e da profissão que escolhi"2. A maioria vence: a tutoria/mentoring continua e já há alguns anos com algumas inovações: juntamos os alunos da Faculdade de Medicina e os da Faculdade de Psicologia, e temos tido resultados muito interessantes que serão publicados futuramente.

Questionei os alunos do primeiro ano de 2020, por e-mail, sobre o Programa de Tutoria/Mentoria e me surpreendi ao constatar que haviam lido os textos enviados sobre o assunto e conversado entre si; tinham grandes expectativas, estavam animados a participar como tutorados/mentorados e principalmente queriam ser ouvidos. Mais de 80 alunos queriam ser ouvidos! 
Isso me surpreendeu e também me amedrontou: "Estamos enclausurados, com aulas on-line, vacinas demoram, e algumas vacinas 'aplicadas' às vezes não têm o líquido! Surreal!". Viver ficou mais perigoso que nos tempos retratados por Guimarães Rosa. Como já ouvi de um aluno: “Viver é para profissional"... e que profissional!!!

Mas o que fazer? Temos obrigação, como mestres, de reconhecer o sofrimento do aluno, ajudá-lo nas mentorias e fora delas, encaminhá-los para atendimento quando necessário. É mister inspirá-los com bons exemplos, encaminhando-os para atividades criativas, esportivas, incentivando o cultivo da espiritualidade e da prática de instrumentos musicais (agressão saindo pelas pontas...).

Rubem Alves ${ }^{3}$ cita que Piaget estudou os moluscos e se interessou muito pela vida deles, seres que nascem frágeis, sem condições de defesa contra agressores, mas que desenvolvem uma casca grossa, um "escudo" forte para que possam sobreviver. Concluiu que o conhecimento é a concha que construímos a fim de sobreviver... "O pensamento se desenvolve como ferramenta." A mente humana também "criou instrumentos" para que o homem pudesse se defender da fome e do ataque agressivo.

\section{CONCLUSÃO}

Sob o ponto de vista da coordenadora e da maioria dos docentes e alunos, a mentoria é importante espaço para o bemestar social e mental do aluno de Medicina, e ferramenta útil no caminho sofrido para se tornar médico competente, confiante e compassivo.
Temos que criar áreas verdes na escola e estimular nossos alunos a criar áreas verdes na mente e instrumental de defesa que lhes possibilitem lidar com seus agressores: medo, raiva, ressentimentos, frustrações, dificuldades na conquista da independência afetiva, medo de não serem capazes de vencer a doença, a morte, medo de enfrentarem o fracasso, principalmente lembrando que o nosso estudante-médico em geral tem, na sua personalidade, traços de onipotência, complexo tanatolítico ${ }^{4}$, perfeccionismo, autocobrança exagerada etc.

A tarefa é difícil, mas compensadora: ajudar o aluno na espinhosa tarefa de tornar-se um ser humano digno, de princípios nobres, um profissional confiante, bem treinado e capacitado a amar, respeitar a vida e curar doentes, não só doenças. Deus nos ilumine!

\section{CONFLITO DE INTERESSES}

Declaro não haver conflito de interesses.

\section{FINANCIAMENTO}

Declaro não haver financiamento.

\section{REFERÊNCIAS}

1. Bellodi PL, Martins MA. Tutoria: mentoring na formação médica. São Paulo: Casa do Psicólogo; 2005.

2. Cruz EMTN. "Confesso que vivi": quatro décadas dedicadas ao estudante de Medicina. Cadernos ABEM 2010; 6: 55-61.

3. Alves R. Sobre moluscos e homens. Folha de S.Paulo; $17 \mathrm{fev} 2002$ [acesso em 25 fev 2021]. Disponível em: https://www1.folha.uol.com.br/fsp/ opiniao/fz1702200208.htm

4. Simon R. O complexo tanatolítico justificando medidas de psicologia preventiva para estudantes de medicina. Bol Psiquiatr. 1971;4(4):113-5. 